\title{
Growth of $\mathrm{MoO}_{3}$ Films by RF Magnetron Sputtering: Studies on the Structural, Optical, and Electrochromic Properties
}

\author{
S. Subbarayudu, V. Madhavi, and S. Uthanna \\ Department of Physics, Sri Venkateswara University, Tirupati 517 502, India \\ Correspondence should be addressed to S. Subbarayudu; srsuguru.phy@gmail.com
}

Received 18 June 2013; Accepted 28 July 2013

Academic Editors: K. Haenen and L. Pusztai

Copyright (c) 2013 S. Subbarayudu et al. This is an open access article distributed under the Creative Commons Attribution License, which permits unrestricted use, distribution, and reproduction in any medium, provided the original work is properly cited.

\begin{abstract}
Molybdenum oxide $\left(\mathrm{MoO}_{3}\right)$ films were deposited on glass and silicon substrates held at temperature $473 \mathrm{~K}$ by $\mathrm{RF}$ magnetron

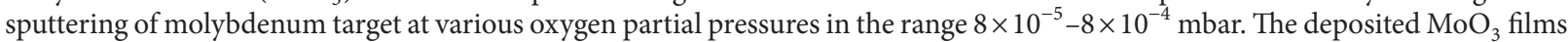
were characterized for their chemical composition, crystallographic structure, surface morphology, chemical binding configuration, and optical properties. The films formed at oxygen partial pressure of $4 \times 10^{-4} \mathrm{mbar}$ were nearly stoichiometric and nanocrystalline $\mathrm{MoO}_{3}$ with crystallite size of $27 \mathrm{~nm}$. The Fourier transform infrared spectrum of the films formed at $4 \times 10^{-4}$ mbar exhibited the characteristics vibrational bands of $\mathrm{MoO}_{3}$. The optical band gap of the films increased from 3.11 to $3.28 \mathrm{eV}$, and the refractive index increased from 2.04 to 2.16 with the increase of oxygen partial pressure from $8 \times 10^{-5}$ to $8 \times 10^{-4}$ mbar, respectively. The electrochromic performance of $\mathrm{MoO}_{3}$ films formed on ITO coated glass substrates was studied and achieved the optical modulation of about $13 \%$ with color efficiency of about $20 \mathrm{~cm}^{2} / \mathrm{C}$.
\end{abstract}

\section{Introduction}

Transition metal oxides constitute an interesting group of semiconducting materials because of their technological applications in various fields such as display devices, optical smart windows, electrochromic devices, and gas sensors $[1,2]$. Among the transition metal oxides, molybdenum oxide $\left(\mathrm{MoO}_{3}\right)$ exhibits interesting structural, chemical, and optical properties. $\mathrm{MoO}_{3}$ finds application as a cathode material in the development of high energy density solid state microbatteries $[3,4]$. It is considered as a chromogenic material since it exhibits electro-, photo-, and gaso chromic (coloration) effects by virtue of which material is of potential for the development of electronic display devices [5]. $\mathrm{MoO}_{3}$ films in nanocrystalline form also find applications in sensors and lubricants [6]. It is also a promising candidate as a back contact layer for cadmium telluride solar cells in superstrate configuration because of its high work function, which possibly reduces the back contact barrier [7]. Various physical thin film deposition techniques such as thermal evaporation $[8,9]$, electron beam evaporation [10, 11], pulsed laser deposition $[12,13]$, and sputtering [14-18] and chemical methods such as electrodeposition [19], chemical vapour deposition [20], spray pyrolysis [21, 22], and sol-gel process [23-25] were employed for the growth of $\mathrm{MoO}_{3}$ films. Among these films deposition techniques, magnetron sputter deposition is an industrially practiced technique for the growth of oxide films. The physical properties of the sputter deposited $\mathrm{MoO}_{3}$ films depend critically on the sputter parameters such as oxygen partial pressure, substrate temperature, substrate bias voltage, sputter power, and sputter pressure. The influence of annealing temperature on the structural and optical properties of RF magnetron sputtered of $\mathrm{MoO}_{3}$ films was earlier reported [18]. In the present investigation, $\mathrm{MoO}_{3}$ films were formed by RF magnetron sputtering of metallic molybdenum target at different oxygen partial pressures. The effect of oxygen partial pressure on the chemical composition, crystallographic structure, surface morphology and optical properties was studied, and the results were reported.

\section{Experimental Details}

2.1. Preparation of $\mathrm{MoO}_{3}$ Thin Films. $\mathrm{MoO}_{3}$ thin films were deposited onto glass and silicon substrates held at temperature of $473 \mathrm{~K}$ by sputtering of pure metallic molybdenum 
target in oxygen and argon gas mixture using reactive RF magnetron sputtering technique. Metallic molybdenum target (99.99\% pure) with $50 \mathrm{~mm}$ diameter and $3 \mathrm{~mm}$ thickness was used as sputter target. The sputter chamber was evacuated using a diffusion pump and rotary pump combination to achieve ultimate pressure of $4 \times 10^{-6}$ mbar. Pressure in the sputter chamber was measured with digital Pirani-Penning gauge combination. Oxygen and argon (99.99\% purity) were used as reactive and sputter gases, respectively, for deposition of $\mathrm{MoO}_{3}$ films. After achieving ultimate pressure, required quantities of oxygen and argon gases were admitted into the sputter chamber through fine controlled needle valves followed by Aalborg mass flow controllers (Model GFC 17). $\mathrm{RF}$ power of $150 \mathrm{~W}$ was supplied to the sputter target using power supply (Advanced Energy Model ATX-600W) for deposition of the experimental films. The sputter parameters fixed during the growth of the $\mathrm{MoO}_{3}$ films are given in Table 1.

2.2. Characterization Methods of $\mathrm{MoO}_{3}$ Thin Films. The $\mathrm{MoO}_{3}$ films formed at various oxygen partial pressure were characterized by studying their chemical composition, crystallographic structure surface morphology, chemical binding configuration, and optical properties. The thickness of the deposited films was measured with a mechanical Veeco Dektak (Model 150) depth profilometer. The chemical composition of the films was analysed with energy dispersive $\mathrm{X}$ ray analysis (Oxford Instruments Inca Penta FETx3) attached to a scanning electron microscope (Carl Zeiss, model EVO MA15). The crystallographic structure of the films was determined by X-ray diffractometer (Bruker D8 advance diffractometer) using copper $K_{\alpha}$ radiation with wavelength of $\lambda=$ $0.15406 \mathrm{~nm}$. The X-ray diffraction profiles were recorded in the $2 \theta$ range $10-60^{\circ}$ in steps of $0.05^{\circ}$. The surface morphology of the films was analysed with a scanning electron microscope (Hitachi SEM Model S-400). The chemical binding configuration of the films formed on silicon substrates was analyzed with Fourier transform infrared spectrophotometer (Nicolet Magana IR 750), recorded in the wavenumber range $300-1500 \mathrm{~cm}^{-1}$. The optical transmittance of the films formed on glass substrates was recorded using UV-Vis-NIR double beam spectrophotometer (Perkin Elmer Spectrophotometer Lambda 950) in the wavelength range $300-1500 \mathrm{~nm}$. The electrochromic properties of the $\mathrm{MoO}_{3}$ films formed at oxygen partial pressure $4 \times 10^{-4}$ mbar were investigated by three-electrode cell with platinum as a counter electrode, $\mathrm{Ag} / \mathrm{AgCl}$ as a reference electrode, and the ITO coated $\mathrm{MoO}_{3}$ films as a working electrode using an EC (Model-CHI 608). The colored and virgin states of the films were measured by UV-Vis-NIR double beam spectrophotometer.

\section{Result and Discussion}

3.1. Deposition Rate. The thickness of the deposited $\mathrm{MoO}_{3}$ films determined by using Veeco depth profilometer was $1.3 \mu \mathrm{m}$ for the films deposited at $8 \times 10^{-5} \mathrm{mbar}$. As the oxygen partial pressure increased from $2 \times 10^{-4}$ to $4 \times 10^{-4}$ mbar, the thickness was increased from 1.8 to $2.2 \mu \mathrm{m}$. Further increase

TABLE 1: Sputter parameters fixed during the growth of the $\mathrm{MoO}_{3}$ films.

Sputter target

Target to substrate distance

Ultimate pressure

Oxygen partial pressure $\left(\mathrm{pO}_{2}\right)$

Substrate temperature $\left(T_{\mathrm{s}}\right)$

Sputter pressure

Sputter power

Deposition time

of oxygen partial pressure to $8 \times 10^{-4}$ mbar decreased the thickness to $1.9 \mu \mathrm{m}$. The deposition rate of the films was calculated from the measured film thickness and duration of deposition. Figure 1 shows the dependence of deposition rate of $\mathrm{MoO}_{3}$ films on the oxygen partial pressure. At low oxygen partial pressure of $8 \times 10^{-5} \mathrm{mbar}$, the deposition rate of $\mathrm{MoO}_{3}$ films was $11.2 \mathrm{~nm} / \mathrm{min}$. The deposition rate gradually increased to $15.5 \mathrm{~nm} / \mathrm{min}$ with the increase of oxygen partial pressure to $2 \times 10^{-4} \mathrm{mbar}$ and reached $18.3 \mathrm{~nm} / \mathrm{min}$ for oxygen partial pressure $4 \times 10^{-4}$ mbar. On further increase of oxygen partial pressure to $8 \times 10^{-4}$, the deposition rate decreased to $16.2 \mathrm{~nm} / \mathrm{min}$. At low oxygen partial pressures, the increase of deposition rate with the increase of oxygen partial pressure was due to the effective reaction between the metallic molybdenum and oxygen and hence, the increase in the deposition rate. At higher oxygen partial pressures, the chemical reaction between the target surface and the reactive oxygen gas forms molybdenum oxide layer on the target which reduced the deposition rate as observed by Mohamed et al. [26]. Scarminio et al. [5] also noticed such an increase of deposition rate with the increase of oxygen partial pressures and then a decrease at higher oxygen partial pressures in RF sputtered $\mathrm{MoO}_{3}$ films. The observed decrease in the deposition rate with increase of oxygen partial pressure was due to target poisoning by oxygen atoms, the negative ion impingement on the target surface reduce the film growth [27].

3.2. Composition Analysis. The chemical composition of the $\mathrm{MoO}_{3}$ films was determined by using energy dispersive X-ray analysis (EDAX). Figure 2 shows the representative EDAX spectra of the $\mathrm{MoO}_{3}$ films deposited at oxygen partial pressures of $8 \times 10^{-5}$ and $4 \times 10^{-4}$ mbar. The chemical constituents present in the $\mathrm{MoO}_{3}$ films formed at different oxygen partial pressures are given in Table 2 . It is seen that the films formed at low oxygen partial pressure of $8 \times 10^{-5} \mathrm{mbar}$ contained less quantity of oxygen required to form a compound of molybdenum oxide. It revealed that the deposited films contained $\mathrm{MoO}_{3}$ along with molybdenum. As the oxygen partial pressure increased to $4 \times 10^{-4} \mathrm{mbar}$, the formed films showed that the atomic ratio of oxygen to molybdenum was 2.98: 1 which indicated that the stoichiometric $\mathrm{MoO}_{3}$ films were deposited at $4 \times 10^{-4}$ mbar. Siciliano et al. [28] also conclude that the atomic ratio of $\mathrm{O}$ and Mo was $3: 1$ in 


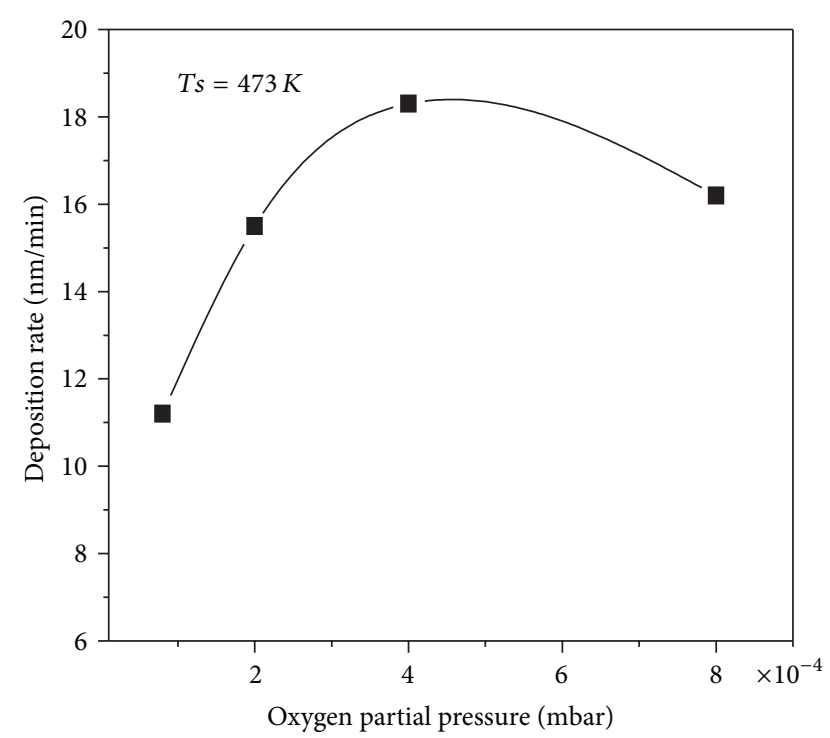

FIgURE 1: Variation of deposition rate of $\mathrm{MoO}_{3}$ films with oxygen partial pressure.

the sputter deposited $\mathrm{MoO}_{3}$ films. It revealed that oxygen partial pressure of $4 \times 10^{-4} \mathrm{mbar}$ is an optimum to achieve stoichiometric $\mathrm{MoO}_{3}$ films. Further with the increase of oxygen partial pressure to $8 \times 10^{-4} \mathrm{mbar}$, the atomic ratio of oxygen to molybdenum was found to be 3.03 . This indicates that the films were overstoichiometric.

3.3. Structural Studies. Crystallographic structure of the films was analyzed by the X-ray diffraction. Figure 3 shows the Xray diffraction (XRD) profiles of the $\mathrm{MoO}_{3}$ films deposited at different oxygen partial pressures. The films formed at low oxygen partial pressure of $8 \times 10^{-5} \mathrm{mbar}$ showed that the X-ray diffraction peak at $2 \theta=26.13^{\circ}$ was related to the (040) reflection of $\mathrm{MoO}_{3}$. Another peak observed at $38.1^{\circ}$ (JCPDS card no. 50-0739) indicated the growth of the mixed phase of $\mathrm{MoO}_{3}$ and $\mathrm{MoO}_{2}$. The presence of this (100) peak revealed that the films formed at low oxygen partial pressure of $8 \times 10^{-5} \mathrm{mbar}$ contained the mixed phase of $\mathrm{MoO}_{2}$ and $\mathrm{MoO}_{3}$ because of insufficient oxygen present in the sputter chamber to achieve stoichiometric films. When oxygen partial pressure increased to $4 \times 10^{-4} \mathrm{mbar}$, the films showed a diffraction peak $2 \theta=12.82^{\circ}$ related to the (020) along with (040) reflections of the orthorhombic $\alpha$ phase of $\mathrm{MoO}_{3}$ (JCPDS card no. 76-1003) in the amorphous background. Thus, the films formed at low oxygen partial pressure were the mixed phase of $\mathrm{MoO}_{2}$ and $\alpha-\mathrm{MoO}_{3}$, and with the increase of oxygen partial pressure the films were transformed into orthorhombic $\alpha$-phase $\mathrm{MoO}_{3}$ nanocrystals within the amorphous background. The films formed at higher oxygen partial pressure of $8 \times 10^{-4}$ mbar showed sharp (020) peak and reduction in the intensity of (040) reflection. Nirupama et al. [29] observed the coexistence of the mixed phase of $\alpha$ - and $\beta-\mathrm{MoO}_{3}$ along with elemental molybdenum at oxygen partial pressures $<2 \times 10^{-4}$ mbar and single $\alpha-\mathrm{MoO}_{3}$ achieved at oxygen partial pressure $\geq 2 \times$
TABLE 2: Chemical composition analysis of $\mathrm{MoO}_{3}$ films analyzed by EDAX.

\begin{tabular}{lccc}
\hline $\begin{array}{l}\text { Oxygen partial pressure } \\
\text { (mbar) }\end{array}$ & $\begin{array}{c}\mathrm{O} \\
\text { (at \%) }\end{array}$ & $\begin{array}{c}\text { Mo } \\
\text { (at \%) }\end{array}$ & O/Mo \\
\hline $8 \times 10^{-5}$ & 72.4 & 27.6 & 2.62 \\
$2 \times 10^{-4}$ & 73.2 & 26.8 & 2.73 \\
$4 \times 10^{-4}$ & 74.8 & 25.2 & 2.97 \\
$8 \times 10^{-4}$ & 75.2 & 24.8 & 3.03 \\
\hline
\end{tabular}

$10^{-4} \mathrm{mbar}$. Subbarayudu et al. [18] have grown polycrystalline $\mathrm{MoO}_{3}$ films with the mixed $\alpha$ - and $\beta$-phases at oxygen partial pressures $1.9 \times 10^{-1}$ and 4 mbar and at substrate temperature of $573 \mathrm{~K}$. On increasing the substrate temperature to $923 \mathrm{~K}$, the films were of $\alpha$-phase $\mathrm{MoO}_{3}$. Gretener et al. [7] deposited $\mathrm{MoO}_{3}$ films with $20 \%$ of oxygen content at substrate temperature $473 \mathrm{~K}$ which consisted of $\mathrm{MoO}_{2}$ and with $50 \%$ of $\mathrm{O}_{2}$ and at higher substrate temperature of $673 \mathrm{~K}$ consisted of $\mathrm{MoO}_{3}$ associated with $\mathrm{Mo}_{9} \mathrm{O}_{26}$ phases. Thus, the grown phases of sputtered $\mathrm{MoO}_{x}$ films strongly depend on oxygen partial pressure prevailed in the sputter chamber during the deposition of the films.

The crystallite size $(L)$ of the films was calculated from the X-ray diffraction reflections by using the Debye-Scherrer relation [30]

$$
L=\frac{0.89 \lambda}{\beta \cos \theta},
$$

where $\lambda$ is the wavelength of the $\mathrm{X}$-ray, $\beta$ the full width at half maximum of diffraction intensity of the diffraction peak measured in radians, and $\theta$ the diffraction angle. The crystallite size of the films increased from 24 to $27 \mathrm{~nm}$ with the increase of oxygen partial pressure from $2 \times 10^{-4}$ to $4 \times 10^{-4}$ mbar, respectively. On further increase of oxygen partial pressure to $8 \times 10^{-4} \mathrm{mbar}$, the crystallite size of the films decreased to $15 \mathrm{~nm}$.

3.4. Surface Morphology. Figure 4 shows the scanning electron microscope images (SEM) of $\mathrm{MoO}_{3}$ films formed at different oxygen partial pressures. $\mathrm{MoO}_{3}$ films deposited at low oxygen partial pressure of $8 \times 10^{-5}$ mbar consisted of grains on cracking background uniformly distributed on the surface. This grain growth was due to $\mathrm{MoO}_{2}$ along with $\mathrm{MoO}_{3}$ at low oxygen partial pressure. When oxygen partial pressure increased to $2 \times 10^{-4}$ mbar, tiny spherical grain growth started. After that, the films exhibited needle shaped grains uniformly distributed on the surface of substrate at an oxygen partial pressure of $4 \times 10^{-4} \mathrm{mbar}$. The size of needle shaped grains was about $800 \mathrm{~nm}$ long and $120 \mathrm{~nm}$ diameter. It is evident that the oxygen partial pressure strongly influenced the surface morphology of the deposited $\mathrm{MoO}_{3}$ films. Further due to the increase of oxygen partial pressure to $4 \times 10^{-4} \mathrm{mbar}$, the films showed uniform large size grains which was attributed to the growth of $\alpha$-phase $\mathrm{MoO}_{3}$. This uniformity of the films was due to the formation of stoichiometric $\alpha-\mathrm{MoO}_{3}$. The films grown at higher oxygen partial pressure of $8 \times 10^{-4} \mathrm{mbar}$ showed the fine grain structure. Ramana and Julien [12] found 


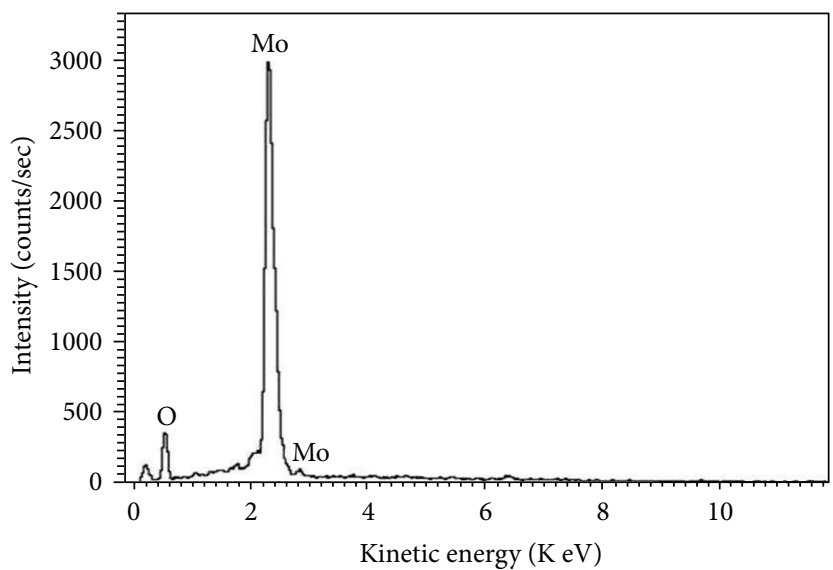

(a)

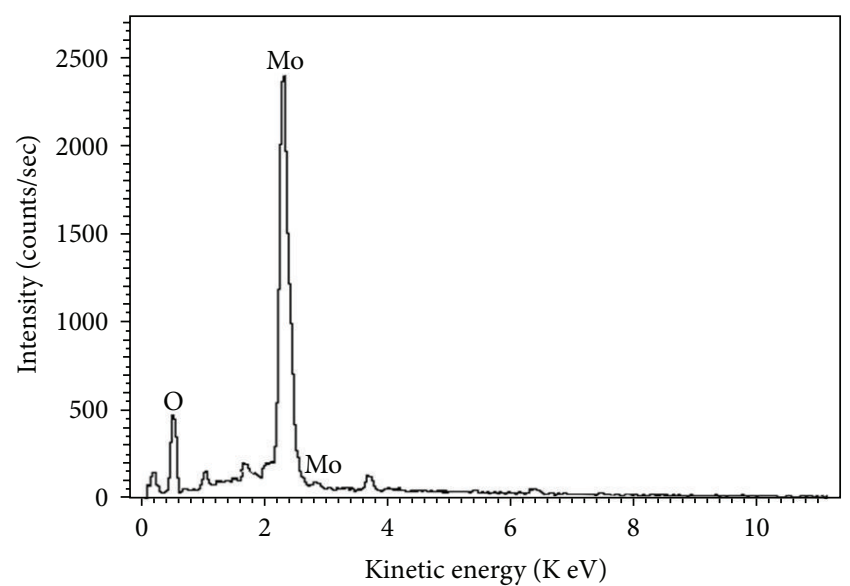

(b)

Figure 2: EDAX spectra of $\mathrm{MoO}_{3}$ films deposited on glass substrates at oxygen partial pressures: (a) $8 \times 10^{-5} \mathrm{mbar}$ and (b) $4 \times 10^{-4} \mathrm{mbar}$.

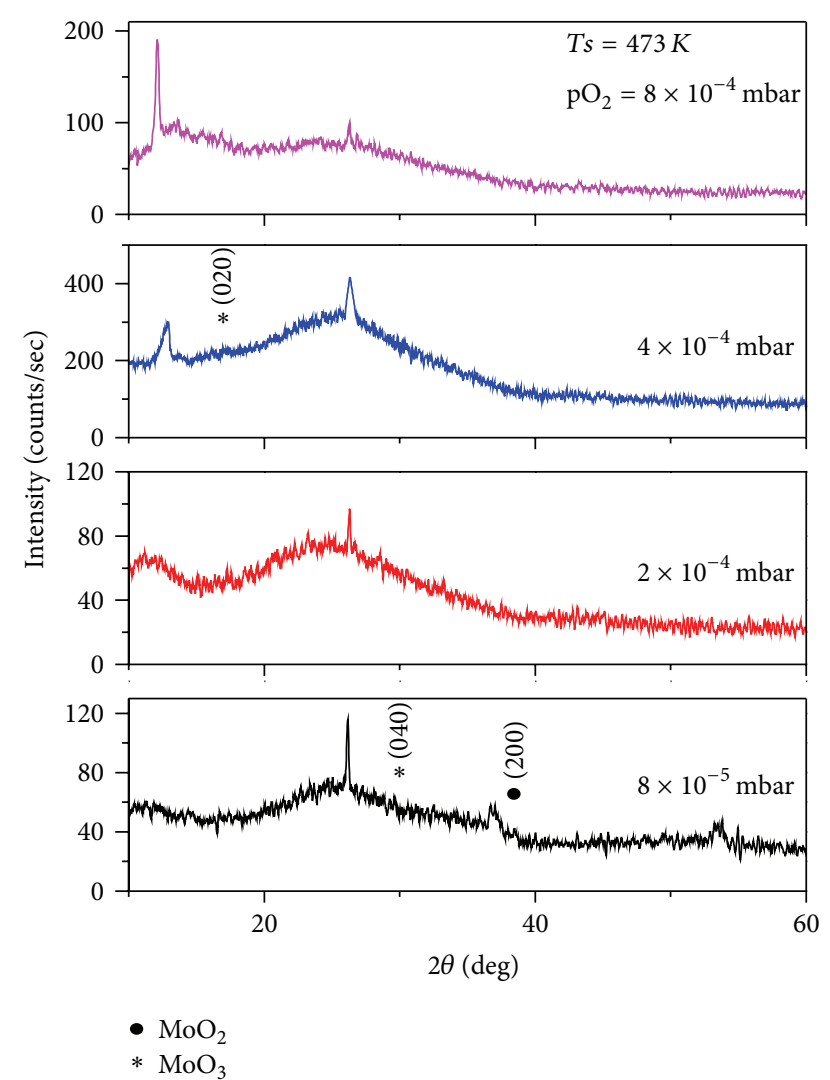

FIGURE 3: XRD profiles of $\mathrm{MoO}_{3}$ films deposited on glass substrates at different oxygen partial pressures.

that the $\mathrm{MoO}_{3}$ films grown at $61 \%$ content of oxygen pressure exhibited small grains along with the thin long bars or needle shape grains due to incomplete oxidation.

3.5. Fourier Transform Infrared Spectroscopy. Fourier transform infrared transmittance spectra of $\mathrm{MoO}_{3}$ films formed on silicon substrates at various oxygen partial pressures were recorded in the wavenumber range $300-1500 \mathrm{~cm}^{-1}$ in order to see the chemical binding configuration in the films. Figure 5 shows the Fourier transform infrared transmittance spectra of $\mathrm{MoO}_{3}$ films formed at different oxygen partial pressures. The FTIR spectra of the films formed at low oxygen partial pressure of $8 \times 10^{-5}$ mbar contained broadband in the wavenumbers between 600 and $1000 \mathrm{~cm}^{-1}$. The absorption band located at $566 \mathrm{~cm}^{-1}$ was due to transverse optical vibrations of $\mathrm{Mo}-\mathrm{O}-\mathrm{Mo}$, and broadband centered around $794 \mathrm{~cm}^{-1}$ was the characteristic bridging vibration of Mo-O. Ivanova et al. [31] observed the transverse optical vibrations of Mo-O-Mo at $558 \mathrm{~cm}^{-1}$. When the oxygen partial pressure increased from $8 \times 10^{-5}$ to $2 \times 10^{-4} \mathrm{mbar}$, the FTIR spectra show the absorption bands at $990,810,689$, and $573 \mathrm{~cm}^{-1}$. The FTIR spectra of the films formed at oxygen partial pressure of $4 \times 10^{-4}$ mbar showed the absorption bands at about 809,689 , and $572 \mathrm{~cm}^{-1}$. The absorption band observed at $811 \mathrm{~cm}^{-1}$ was attributed to the bridging vibrations of $\mathrm{Mo}=\mathrm{O}$ and indicated that the existence of $\mathrm{Mo}^{6+}$ oxidation state was related to $\alpha$ phase $\mathrm{MoO}_{3}$. The films deposited at oxygen partial pressure of $8 \times 10^{-4}$ mbar showed a shift in the absorption bands to 820,687 , and $558 \mathrm{~cm}^{-1}$. The intensity of the absorption band seen at $990 \mathrm{~cm}^{-1}$ was associated with the $\mathrm{Mo}=\mathrm{O}$ stretching vibration. Nirupama et al. [29] noticed that the absorption bands at 894 and $1002 \mathrm{~cm}^{-1}$ were corresponding to the growth of $\alpha$-phase $\mathrm{MoO}_{3}$ in DC magnetron sputtered $\mathrm{MoO}_{3}$ films formed at oxygen partial pressure of $4 \times 10^{-4} \mathrm{mbar}$. These studies confirmed that the oxygen partial pressure of $4 \times 10^{-4} \mathrm{mbar}$ is an optimum to produce the films with stoichiometric $\alpha$-phase $\mathrm{MoO}_{3}$.

3.6. Optical Properties. Figure 6 shows the wavelength dependence optical transmittance of the $\mathrm{MoO}_{3}$ films formed at different oxygen partial pressures. The optical transmittance of the films formed at low oxygen partial pressure of $8 \times 10^{-5} \mathrm{mbar}$ exhibited the average optical transmittance $<50 \%$ about the fundamental optical 


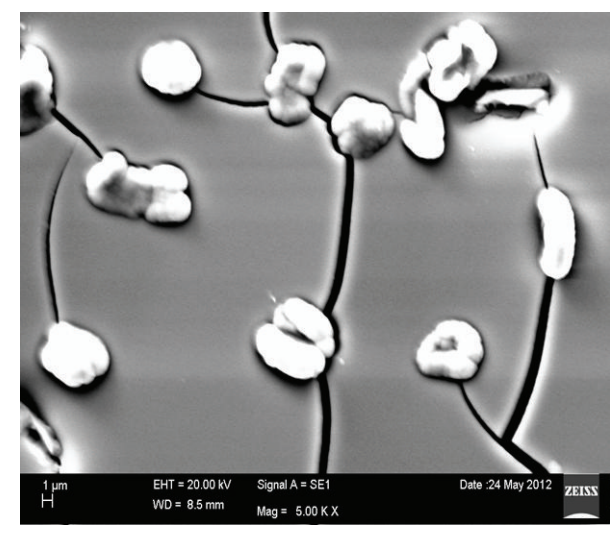

(a)

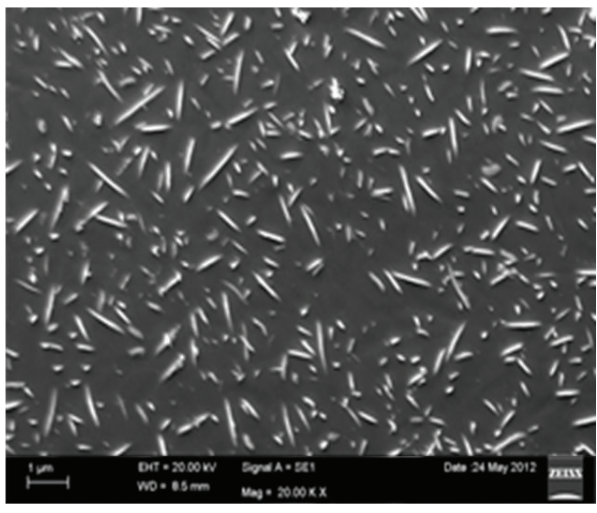

(c)

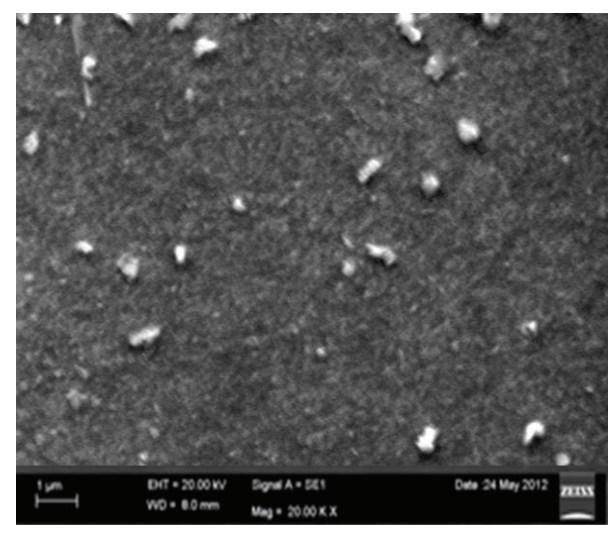

(b)

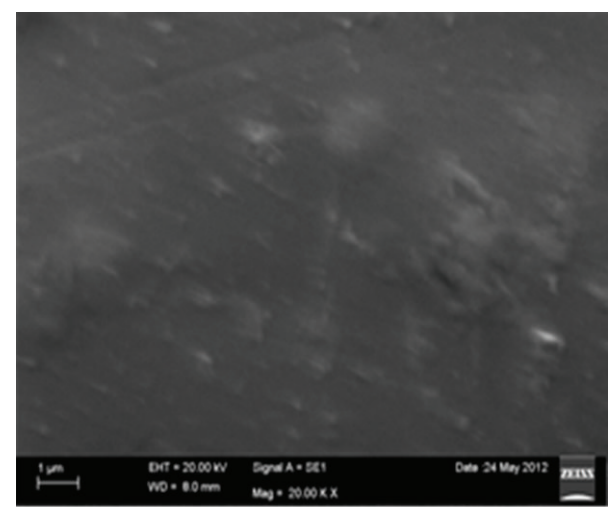

(d)

Figure 4: SEM images of $\mathrm{MoO}_{3}$ films formed on glass substrates at oxygen partial pressures: (a) $8 \times 10^{-5} \mathrm{mbar},(\mathrm{b}) 2 \times 10^{-4} \mathrm{mbar}$, (c) $4 \times$ $10^{-4}$ mbar, and (d) $8 \times 10^{-4}$ mbar.

absorption edge. This low optical transmittance at low oxygen partial pressure of $8 \times 10^{-5}$ mbar was due to the formation of substoinchiometric $\mathrm{MoO}_{3}$ films which characterize the blue color due to the oxygen ion vacancies $[29,32]$. The broadband absorption above wavelength $500 \mathrm{~nm}$ was mainly due to the presence of $\mathrm{MoO}_{2}$ atoms which act as scattering centers of light and hence the decrease in the optical transmittance. As the oxygen partial pressure increased to $4 \times 10^{-4} \mathrm{mbar}$, the optical transmittance increased to about $85 \%$ due to oxygen ion vacancies decrease, and the films transformed into nearly stoichiometric $\alpha-\mathrm{MoO}_{3}$ films. As the oxygen partial pressure increased to $4 \times 10^{-4}$ and $8 \times 10^{-4}$ mbar, there was not much variation in the optical transmittance due to the formation of $\mathrm{MoO}_{3}$ films as conformed by the EDAX data. The fundamental optical absorption edge in the films was observed in the wavelength range $300-400 \mathrm{~nm}$. The optical absorption edge of the films shifted towards lower wavelength side with the increase of oxygen partial pressure.

The optical absorption coefficient $(\alpha)$ of the films was evaluated from the optical transmittance $(T)$ data using the relation:

$$
\alpha=-\left(\frac{1}{t}\right) \ln (T),
$$

where $t$ is the film thickness. The optical band gap $\left(E_{g}\right)$ of the films was evaluated from the optical absorption coefficient using the Tauc relation [33] assuming that the direct transition was takes place in these films

$$
(\alpha h v)=A\left(h v-E_{g}\right)^{1 / 2} .
$$

The plots of $(\alpha h v)^{2}$ versus photon energy $(h v)$ of the films formed at different oxygen partial pressures are shown in Figure 7. The optical band gap of the films was determined from the plot of $(\alpha h v)^{2}$ versus photon energy $(h v)$. The extrapolation of the linear portion of plots of $(\alpha h v)^{2}$ versus photon energy to $\alpha=0$ yields the optical band gap of the films. The optical band gap of the $\mathrm{MoO}_{3}$ films formed at low oxygen partial pressure of $8 \times 10^{-5}$ was $3.11 \mathrm{eV}$, and it increased from 3.23 to $3.28 \mathrm{eV}$ with the increase of oxygen partial pressure from $2 \times 10^{-4}$ to $4 \times 10^{-4}$ mbar, respectively. On further increase of oxygen partial pressure to $8 \times 10^{-4} \mathrm{mbar}$, the optical band gap of the films reached $3.35 \mathrm{eV}$. The low value of the optical band gap of the films formed at low oxygen partial pressures was due to the formation of substoichiometric films, which is the mixed phase of $\mathrm{MoO}_{2}$ and $\mathrm{MoO}_{3}$. The films formed at oxygen partial pressure of $4 \times 10^{-4} \mathrm{mbar}$ were of nearly stoichiometric $\mathrm{MoO}_{3}$ films. These $\mathrm{MoO}_{3}$ films exhibited the optical band gap of 


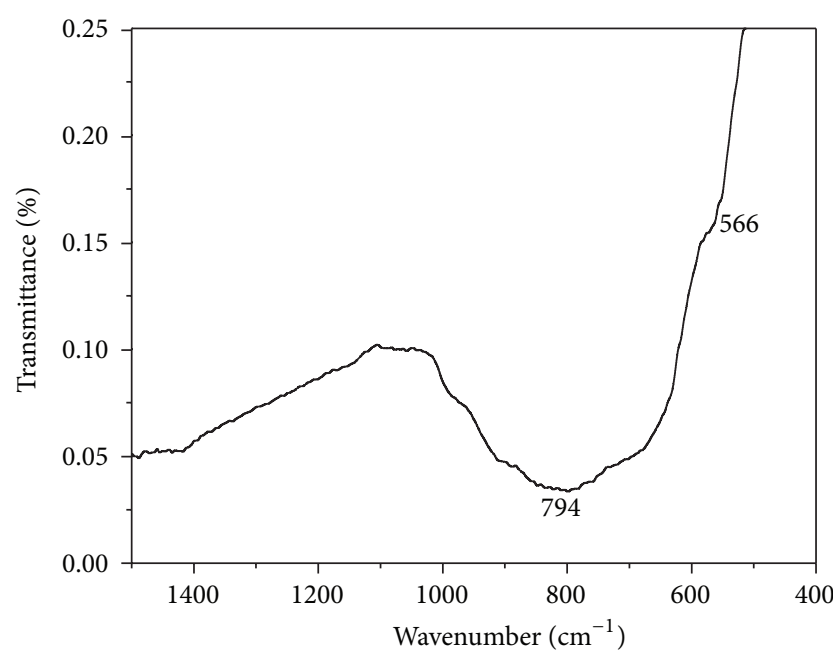

(a)

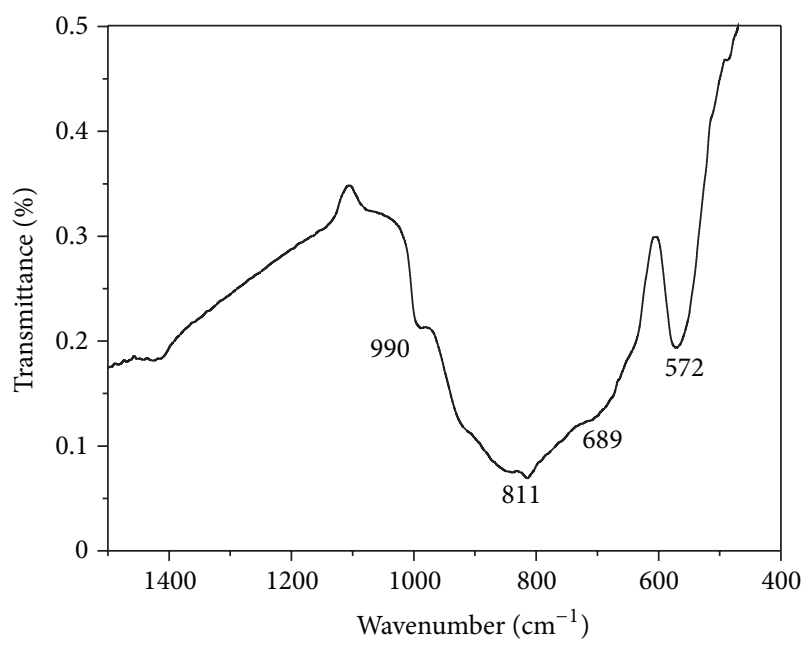

(c)

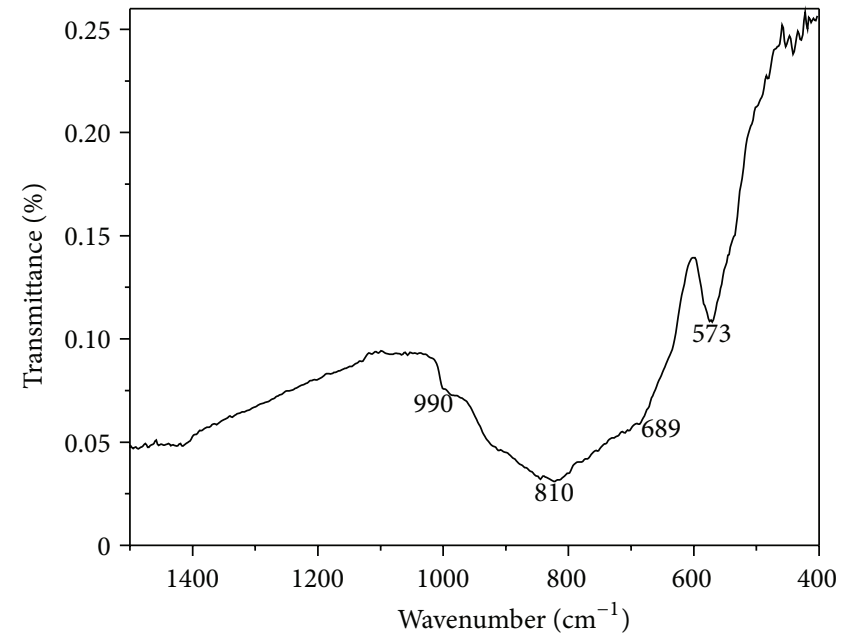

(b)

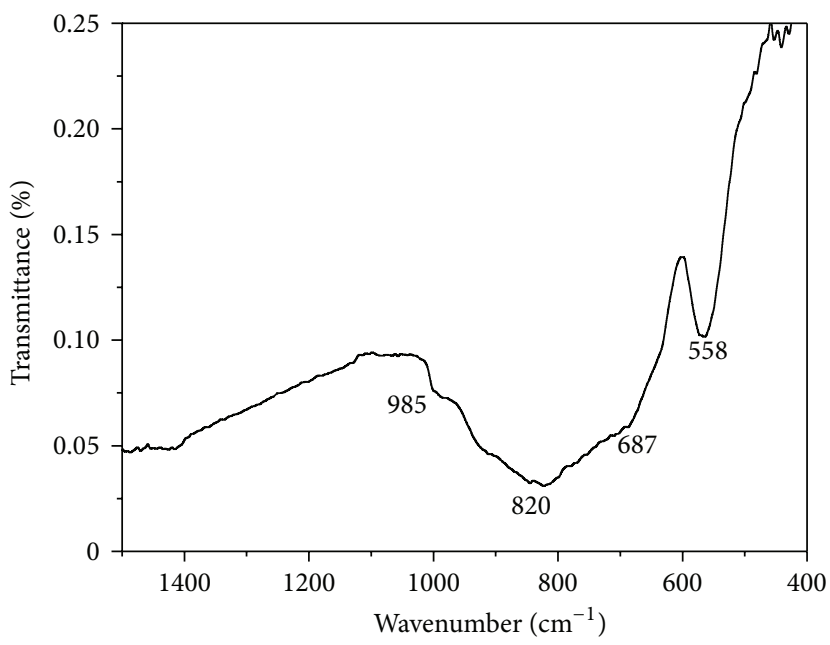

(d)

FIGURE 5: FTIR spectra of $\mathrm{MoO}_{3}$ films formed on silicon substrates at oxygen partial pressures: (a) $8 \times 10^{-5} \mathrm{mbar}$, (b) $2 \times 10^{-4} \mathrm{mbar}(\mathrm{c})$ $4 \times 10^{-4}$ mbar, and (d) $8 \times 10^{-4}$ mbar.

$3.28 \mathrm{eV}$. In the literature, Okumu et al. [34] observed that the optical band gap of the $\mathrm{MoO}_{3}$ films increased from 3.0 to $3.2 \mathrm{eV}$ with the increase of oxygen partial pressure from $8 \times 10^{-2}$ to $1.2 \times 10^{-1}$ mbar in DC magnetron sputtering. Mohamed and Venkataraj [17] noticed that the value of the optical band gap of the films initially increased from 2.64 to $2.69 \mathrm{eV}$ with the increase of oxygen partial pressure from $0.17 \times 10^{-5}$ to $2.6 \times 10^{-1} \mathrm{mbar}$ and then decreased to $2.67 \mathrm{eV}$ with further increase to $6.4 \times 10^{-1}$ mbar which was due to the reduction of defect centers and hence improved in stoichiometry. Boudaoud et al. [22] achieved a high optical band gap of $3.35 \mathrm{eV}$ in spray pyrolysis deposited $\mathrm{MoO}_{3}$ films. It is to be noted that low optical band gap values between 2.60 and $2.70 \mathrm{eV}$ in DC magnetron sputtered [17] and RF magnetron sputtered [35] films were due to the growth of $\beta$ $\mathrm{MoO}_{3}$.

The refractive index $(n)$ of the films was determined from the optical transmittance interference data employing
Swanepoel's envelope method used in the following relation [36],

$$
\begin{gathered}
n(\lambda)=\left[N+\left(N^{2}-n_{0}^{2} n_{1}^{2}\right)^{1 / 2}\right]^{1 / 2}, \\
N=2 n_{0} n_{1}\left[\frac{\left(T_{M}-T_{m}\right)}{T_{M} T_{m}}\right]+\left[\frac{\left(n_{0}^{2}+n_{1}^{2}\right)}{2}\right],
\end{gathered}
$$

where $T_{M}$ and $T_{m}$ are the optical transmittance maxima and minima and $n_{0}$ and $n_{1}$ are the refractive indices of air and substrate, respectively. Figure 8 shows the wavelength dependence of refractive index of $\mathrm{MoO}_{3}$ films formed at different oxygen partial pressures. In general, the refractive index of the $\mathrm{MoO}_{3}$ films decreased with the increase of wavelength. The refractive index of $\mathrm{MoO}_{3}$ films (at the wavelength of $500 \mathrm{~nm}$ ) increased from 2.04 to 2.16 with the increase of oxygen partial pressure from $8 \times 10^{-5}$ to $8 \times$ 


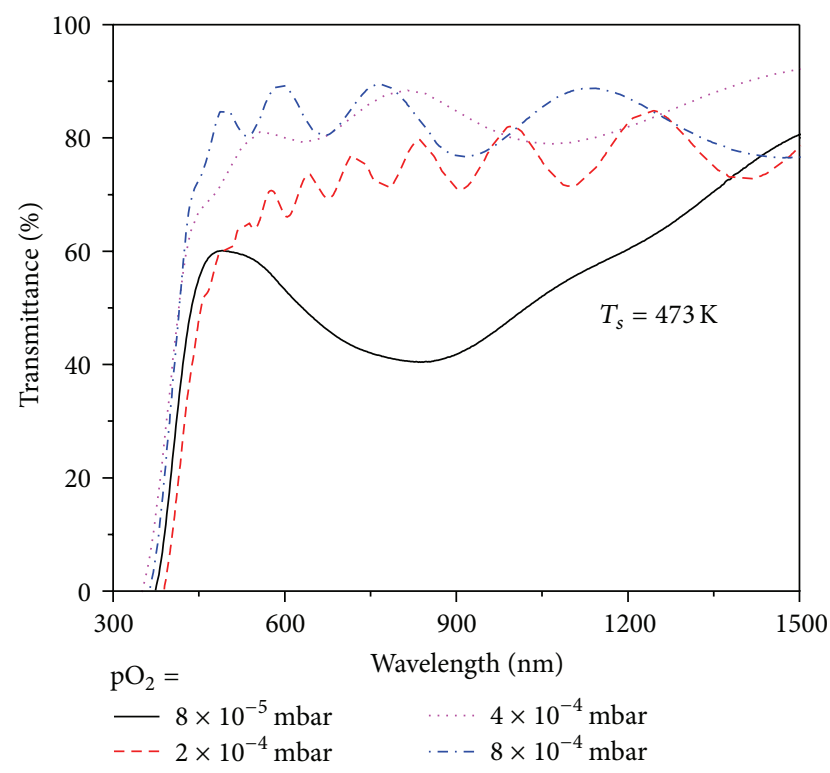

FIgURE 6: Variation of optical transmittance of $\mathrm{MoO}_{3}$ films deposited on glass substrates at different oxygen partial pressures.

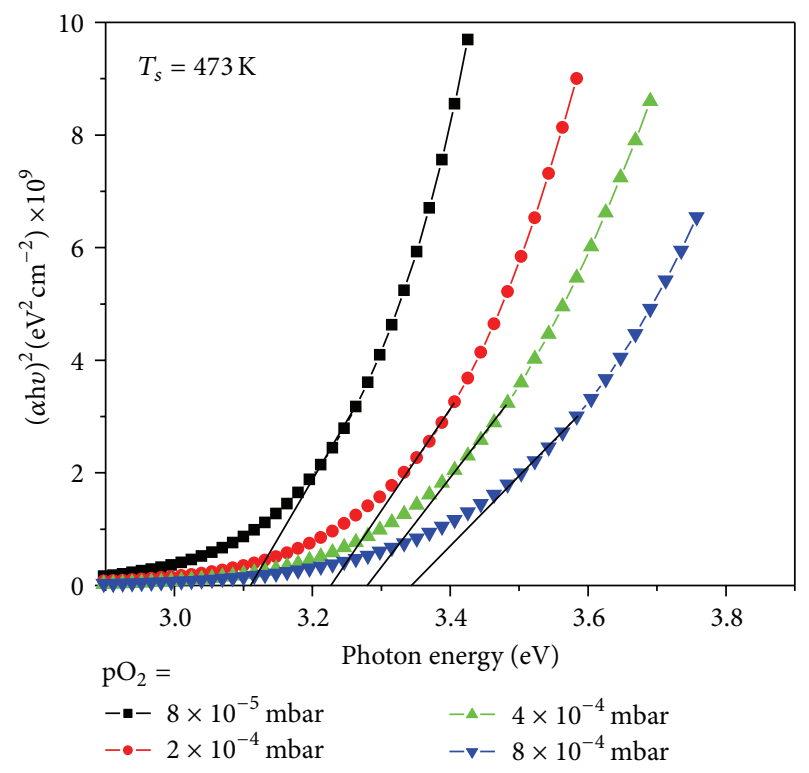

FIGURe 7: Plot of $(\alpha h v)^{2}$ versus photon energy $(h v)$ of $\mathrm{MoO}_{3}$ films deposited on glass substrates at different oxygen partial pressures.

$10^{-4} \mathrm{mbar}$, respectively. The low value of refractive index at low oxygen partial pressure of $8 \times 10^{-5} \mathrm{mbar}$ was due to the presence of $\mathrm{MoO}_{2}$ along with the $\mathrm{MoO}_{3}$. The increase in the refractive index at higher oxygen partial pressures was due to the formation of single phase $\alpha-\mathrm{MoO}_{3}$ and increase in the packing density of the films. It is to be noted from the literature that the refractive index value of 1.8 was achieved by Reyes-Betanzo et al. [37] in thermal evaporation films, while Cárdenas et al. [38] reported 1.9 in pulsed laser deposited films. The refractive index of the DC magnetron sputtered

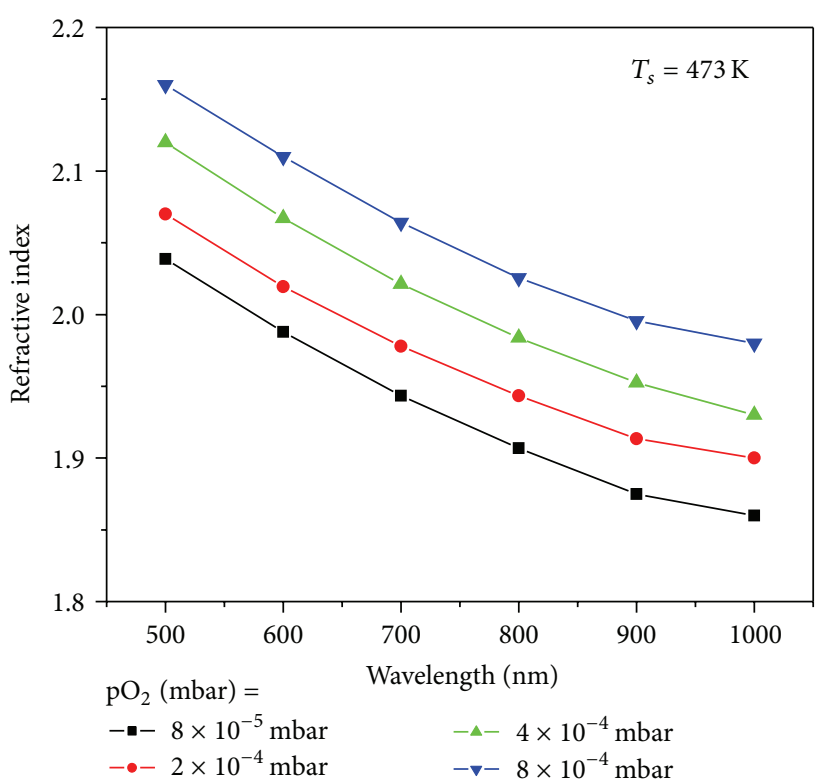

FIGURE 8: Wavelength dependence of refractive index of $\mathrm{MoO}_{3}$ films deposited on glass substrates at different oxygen partial pressures.

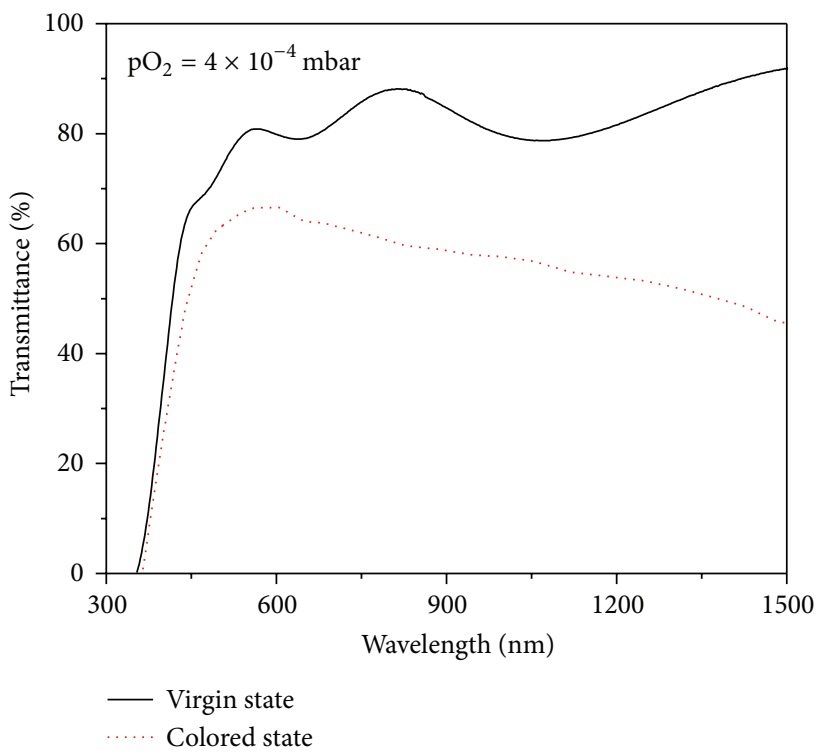

FIGURE 9: Optical transmittance spectra of virgin and colored states of $\mathrm{MoO}_{3}$ film deposited on glass substrates at oxygen partial pressure of $4 \times 10^{-4}$ mbar.

$\mathrm{MoO}_{3}$ films increased from 2.03 to 2.10 with the increase of substrate temperature from 303 to $573 \mathrm{~K}$ [14].

3.7. Electrochromic Properties. In order to study the electrochromic properties, the stoichiometric $\mathrm{MoO}_{3}$ films were formed on ITO coated glass substrates at oxygen partial pressure of $4 \times 10^{-4} \mathrm{mbar}$. The electrochromic properties of the films were investigated by three-electrode cell, with platinum as a counter electrode, $\mathrm{Ag} / \mathrm{AgCl}$ as a reference electrode and the indium tin oxide coated $\mathrm{MoO}_{3}$ films as a 
working electrode using an electrochromic cell model (HI 608). The colored and virgin states of the films were measured by UV-Vis-NIR spectrophotometer. In the electrochromism, the coloration is due to the reduction of $\mathrm{Mo}^{6+}$ to $\mathrm{Mo}^{5+}$ state by insertion of $\mathrm{Li}^{+}$ions into the $\mathrm{MoO}_{3}$ films. In the reverse scan, the virgin state can be achieved by the intercalation charge removed from the films, resulting in the virgin state due to the oxidation of $\mathrm{Mo}^{5+}$ to $\mathrm{Mo}^{6+}$ state. Figure 9 shows the colored and virgin states of the $\mathrm{MoO}_{3}$ film formed at oxygen partial pressure of $4 \times 10^{-4}$ mbar. The optical modulation $(\Delta T)$ of the films at $550 \mathrm{~nm}$ is about $13 \%$. This optical modulation is mainly dependent on the quantity of $\mathrm{Li}^{+}$insertion into the $\mathrm{MoO}_{3}$ films. The color efficiency $(\eta)$ at a particular wavelength correlated to the optical contrast; that is, the change in optical density with charges intercalated per unit electrode area and can be expressed with relation [39]:

$$
\eta=\frac{\log \left(T_{b} / T_{c}\right)}{(Q / A)}=\frac{(\Delta O D)}{(Q / A)},
$$

where $T_{b}$ is the bleaching transmittance, $T_{c}$ the colored transmittance, $Q$ the charge inserted into the films, and $A$ the area of the films. The color efficiency of the $\mathrm{MoO}_{3}$ film formed at oxygen partial pressure of $4 \times 10^{-4}$ mbar was $20 \mathrm{~cm}^{2} / \mathrm{C}$. Lin et al. [40] reported that the coloration efficiency achieved a value of $25.1 \mathrm{~cm}^{2} / \mathrm{C}$ in the $\mathrm{MoO}_{3}$ films formed at room temperature subsequently annealed in air at $573 \mathrm{~K}$.

\section{Conclusions}

Thin films of molybdenum oxide were deposited on glass and silicon substrates held at temperature of $473 \mathrm{~K}$ by RF magnetron sputtering method. The films were formed by sputtering of metallic molybdenum target at various oxygen partial pressures in the range $8 \times 10^{-5}-8 \times 10^{-4}$ mbar. The energy dispersive $\mathrm{X}$-ray analysis revealed that the films formed at oxygen partial pressure of $4 \times 10^{-4}$ mbar were nearly stoichiometric. X-ray diffraction studies indicated that the films formed at oxygen partial pressure $<4 \times 10^{-4}$ mbar were the mixed phase of $\mathrm{MoO}_{2}$ and $\mathrm{MoO}_{3}$, while those deposited at $4 \times 10^{-4}$ mbar were single phase $\alpha-\mathrm{MoO}_{3}$ with crystallite size of $28 \mathrm{~nm}$. Scanning electron microscopic studies revealed that the films grown at $4 \times 10^{-4} \mathrm{mbar}$ exhibited that the grown grains are of needle shape grains with size of about $800 \mathrm{~nm}$. The Fourier transform infrared transmittance spectra indicated the presence of characteristic vibrations of $\mathrm{MoO}_{3}$ in the films formed at oxygen partial pressure $\geq 4 \times 10^{-4}$ mbar. The optical band gap of the films increased from 3.11 to $3.28 \mathrm{eV}$, and the refractive index of the films increased from 2.04 to 2.16 with increase of oxygen partial pressure from $8 \times 10^{-5}$ to $8 \times 10^{-4}$ mbar, respectively. The electrochromic performance of the stoichiometric $\mathrm{MoO}_{3}$ films formed on ITO coated glass substrates was studied and achieved the optical modulation of about $13 \%$ with color efficiency of about $20 \mathrm{~cm}^{2} / \mathrm{C}$.

\section{References}

[1] C. G. Granqvist, Handbook of Inorganic Electrochromic Materials, Elsevier, Amsterdam, The Netherlands, 1995.

[2] K. Hinokuma, A. Kishimoto, and T. Kudo, "Coloration dynamics of spin-coated $\mathrm{MoO}_{3} \cdot \mathrm{nH}_{2} \mathrm{O}$ electrochromic films fabricated from peroxo-polymolybdate solution," Journal of The Electrochemical Society, vol. 141, pp. 876-879, 1994.

[3] C. Julien, Lithium Batteries, New Materials, Developments and Perspectives, Edited by: G. Pistoria, North Holland, Amsterdam, The Netherlands, 1994.

[4] W. Li, F. Cheng, Z. Tao, and J. Chen, "Vapor-transportation preparation and reversible lithium intercalation/deintercalation of $\alpha-\mathrm{MoO}_{3}$ microrods," Journal of Physical Chemistry B, vol. 110, no. 1, pp. 119-124, 2006.

[5] J. Scarminio, A. Lourenço, and A. Gorenstein, "Electrochromism and photochromism in amorphous molybdenum oxide films," Thin Solid Films, vol. 302, no. 1-2, pp. 66-70, 1997.

[6] A. K. Prasad, D. J. Kubinski, and P. I. Gouma, "Comparison of sol-gel and ion beam deposited $\mathrm{MoO}_{3}$ thin film gas sensors for selective ammonia detection," Sensors and Actuators B, vol. 93, no. 1-3, pp. 25-30, 2003.

[7] C. Gretener, J. Perrenouda, L. Kranza et al., "Development of MoOx thin films as back contact buffer for CdTe solar cells in substrate configuration," Thin Solid Films, vol. 535, pp. 193-197, 2013.

[8] T. S. Sian and G. B. Reddy, "Stoichiometric amorphous $\mathrm{MoO}_{3}$ films: a route to high performance electrochromic devices," Journal of Applied Physics, vol. 98, no. 2, Article ID 026104, 2005.

[9] W.-Q. Yang, Z.-R. Wei, X.-H. Zhu, and D.-Y. Yang, "Strong influence of substrate temperature on the growth of nanocrystalline $\mathrm{MoO}_{3}$ thin films," Physics Letters A, vol. 373, no. 43, pp. 39653968, 2009.

[10] R. Sivakumar, R. Gopalakrishnan, M. Jayachandran, and C. Sanjeeviraja, "Characterization on electron beam evaporated $\alpha-\mathrm{MoO}_{3}$ thin films by the influence of substrate temperature," Current Applied Physics, vol. 7, no. 1, pp. 51-59, 2007.

[11] V. K. Sabhapathi, O. M. Hussain, S. Uthanna et al., "A.c. conductivity studies on $\mathrm{Al} / \mathrm{MoO}_{3} / \mathrm{Al}$ sandwich structures," Materials Science and Engineering B, vol. 32, no. 1-2, pp. 93-97, 1995.

[12] C. V. Ramana and C. M. Julien, "Chemical and electrochemical properties of molybdenum oxide thin films prepared by reactive pulsed-laser assisted deposition," Chemical Physics Letters, vol. 428, no. 1-3, pp. 114-118, 2006.

[13] C. V. Ramana, V. V. Atuchin, V. G. Kesler et al., "Growth and surface characterization of sputter-deposited molybdenum oxide thin films," Applied Surface Science, vol. 253, no. 12, pp. 5368-5374, 2007.

[14] S. Uthanna, V. Nirupama, and J. F. Pierson, "Substrate temperature influenced structural, electrical and optical properties of dc magnetron sputtered $\mathrm{MoO}_{3}$ films," Applied Surface Science, vol. 256, no. 10, pp. 3133-3137, 2010.

[15] K. Srinivasarao, B. Rajini Kanth, and P. K. Mukhopadhyay, "Optical and IR studies on r.f. magnetron sputtered ultra-thin $\mathrm{MoO}_{3}$ films," Applied Physics A, vol. 96, no. 4, pp. 985-990, 2009.

[16] I. Navas, R. Vinodkumar, K. J. Lethy et al., "Growth and characterization of molybdenum oxide nanorods by RF magnetron sputtering and subsequent annealing," Journal of Physics D, vol. 42, no. 17, Article ID 175305, 2009.

[17] S. H. Mohamed and S. Venkataraj, "Thermal stability of amorphous molybdenum trioxide films prepared at different 
oxygen partial pressures by reactive DC magnetron sputtering," Vacuum, vol. 81, no. 5, pp. 636-643, 2007.

[18] S. Subbarayudu, V. Madhavi, and S. Uthanna, "Post-deposition annealing controlled structural and optical properties of RF magnetron sputtered $\mathrm{MoO}_{3}$ films," Advanced Materials Letters, vol. 4, no. 8, pp. 637-642, 2013.

[19] R. S. Patil, M. D. Uplane, and P. S. Patil, "Structural and optical properties of electrodeposited molybdenum oxide thin films," Applied Surface Science, vol. 252, no. 23, pp. 8050-8056, 2006.

[20] T. Itoh, I. Matsubara, W. Shin, N. Izu, and M. Nishibori, "Preparation of layered organic-inorganic nanohybrid thin films of molybdenum trioxide with polyaniline derivatives for aldehyde gases sensors of several tens ppb level," Sensors and Actuators B, vol. 128, no. 2, pp. 512-520, 2008.

[21] H. M. Martinez, J. Torres, L. D. Lopez Correno, and M. E. Rodriguez-Garcia, "Effect of the substrate temperature on the physical properties of molybdenum tri-oxide thin films obtained through the spray pyrolysis technique," Materials Characterization, vol. 75, pp. 184-193, 2013.

[22] L. Boudaoud, N. Benramdane, R. Desfeux, B. Khelifa, and C. Mathieu, "Structural and optical properties of $\mathrm{MoO}_{3}$ and $\mathrm{V}_{2} \mathrm{O}_{5}$ thin films prepared by Spray Pyrolysis," Catalysis Today, vol. 113, no. 3-4, pp. 230-234, 2006.

[23] C.-S. Hsu, C.-C. Chan, H.-T. Huang, C.-H. Peng, and W.-C. $\mathrm{Hsu}$, "Electrochromic properties of nanocrystalline $\mathrm{MoO}_{3}$ thin films," Thin Solid Films, vol. 516, no. 15, pp. 4839-4844, 2008.

[24] J. Kaur, V. D. Vankar, and M. C. Bhatnagar, "Effect of $\mathrm{MoO}_{3}$ addition on the $\mathrm{NO}_{2}$ sensing properties of $\mathrm{SnO}_{2}$ thin films," Sensors and Actuators B, vol. 133, no. 2, pp. 650-655, 2008.

[25] M. Dhanasankar, K. K. Purushothaman, and G. Muralidharan, "Effect of temperature of annealing on optical, structural and electrochromic properties of sol-gel dip coated molybdenum oxide films," Applied Surface Science, vol. 257, no. 6, pp. 20742079, 2011.

[26] S. H. Mohamed, O. Kappertz, J. M. Ngaruiya, T. P. Leervad Pedersen, R. Drese, and M. Wuttig, "Correlation between structure, stress and optical properties in direct current sputtered molybdenum oxide films," Thin Solid Films, vol. 429, no. 1-2, pp. 135-143, 2003.

[27] M. S. Oh, B. S. Yang, J. H. Lee et al., "Improvement of electrical and optical properties of molybdenum oxide thin films by ultralow pressure sputtering method," Journal of Vacuum Science \& Technology A, vol. 30, no. 3, Article ID 031501, 7 pages, 2012.

[28] T. Siciliano, A. Tepore, E. Filippo, G. Micocci, and M. Tepore, "Characteristics of molybdenum trioxide nanobelts prepared by thermal evaporation technique," Materials Chemistry and Physics, vol. 114, no. 2-3, pp. 687-691, 2009.

[29] V. Nirupama, K. R. Gunasekhar, B. Sreedhar, and S. Uthanna, "Effect of oxygen partial pressure on the structural and optical properties of dc reactive magnetron sputtered molybdenum oxide films," Current Applied Physics, vol. 10, no. 1, pp. 272-278, 2010.

[30] B. D. Cullity, Elements of X-Ray Diffraction, Addison Wesley, London, UK, 2nd edition, 1978.

[31] T. Ivanova, K. A. Gesheva, and A. Szekeres, "Structure and optical properties of CVD molybdenum oxide films for electrochromic application," Journal of Solid State Electrochemistry, vol. 7, no. 1, pp. 21-24, 2002.

[32] V. K. Sabhapathi, O. M. Hussain, P. S. Reddy et al., "Optical absorption studies in molybdenum trioxide thin films," Physica Status Solidi A, vol. 148, no. 1, pp. 167-173, 1995.
[33] J. Tauc, Amourphous and Liquid Semiconductor, Plenum Press, New York, NY, USA, 1974.

[34] J. Okumu, F. Koerfer, C. Salinga, T. P. Pedersen, and M. Wuttig, "Gasochromic switching of reactively sputtered molybdenumoxide films: a correlation between film properties and deposition pressure," Thin Solid Films, vol. 515, no. 4, pp. 13271333, 2006.

[35] N. Miyata and S. Akiyoshi, "Preparation and electrochromic properties of rf-sputtered molybdenum oxide films," Journal of Applied Physics, vol. 58, no. 4, pp. 1651-1655, 1985.

[36] R. Swanepoel, "Determination of the thickness and optical constants of amorphous silicon," Journal of Physics E, vol. 16, no. 12, pp. 1214-1222, 1983.

[37] C. Reyes-Betanzo, J. L. Herrera-Pérez, G. H. Cocoletzi, and O. Zelaya-Angel, "Refractive index of colored films of molybdenum trioxide," Journal of Applied Physics, vol. 88, no. 1, pp. 223$226,2000$.

[38] R. Cárdenas, J. Torres, and J. E. Alfonso, "Optical characterization of $\mathrm{MoO}_{3}$ thin films produced by continuous wave $\mathrm{CO}_{2}$ laser-assisted evaporation," Thin Solid Films, vol. 478, no. 1-2, pp. 146-151, 2005.

[39] C. G. Granqvist, "Electrochromic tungsten oxide films: review of progress 1993-1998," Solar Energy Materials and Solar Cells, vol. 60, no. 3, pp. 201-262, 2000.

[40] S.-Y. Lin, C.-M. Wang, K.-S. Kao, Y.-C. Chen, and C.-C. Liu, "Electrochromic properties of $\mathrm{MoO}_{3}$ thin films derived by a solgel process," Journal of Sol-Gel Science and Technology, vol. 53, no. 1, pp. 51-58, 2010. 

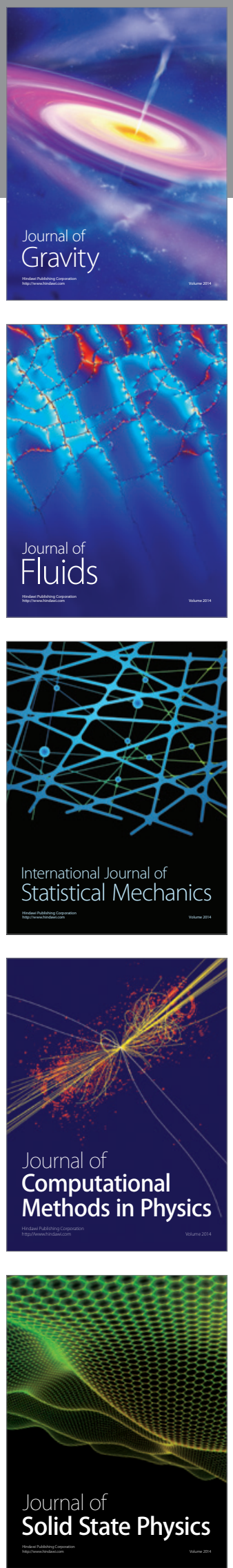

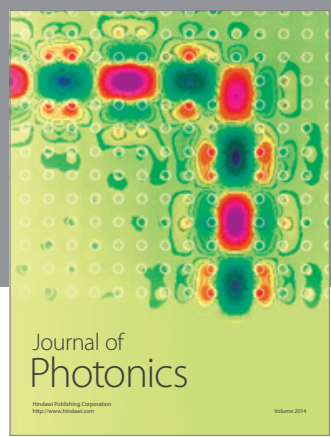

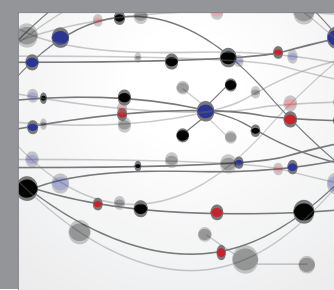

The Scientific World Journal

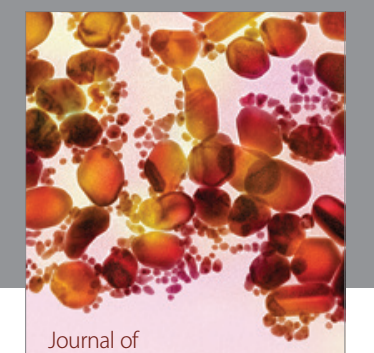

Soft Matter
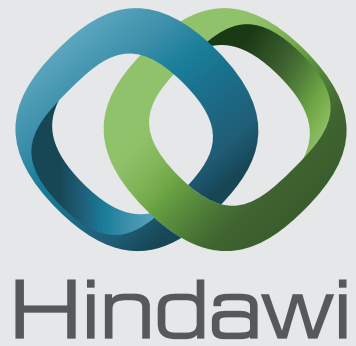

Submit your manuscripts at

http://www.hindawi.com
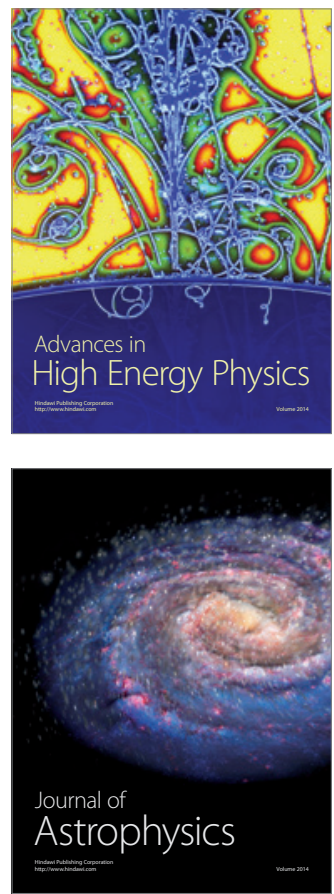
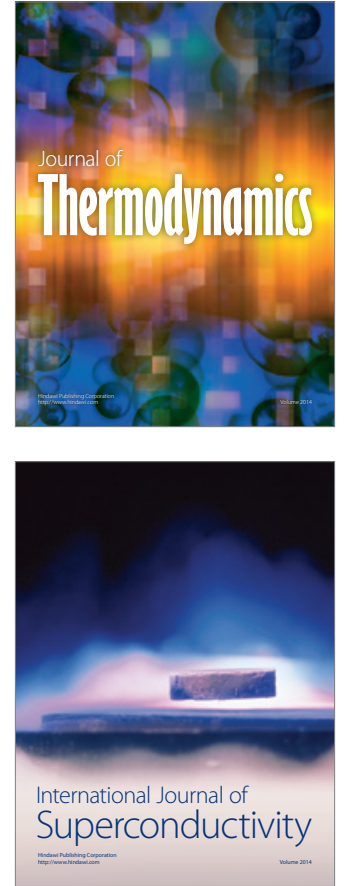
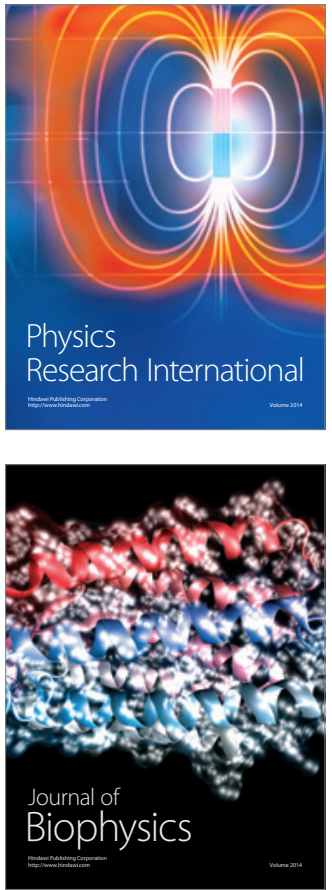
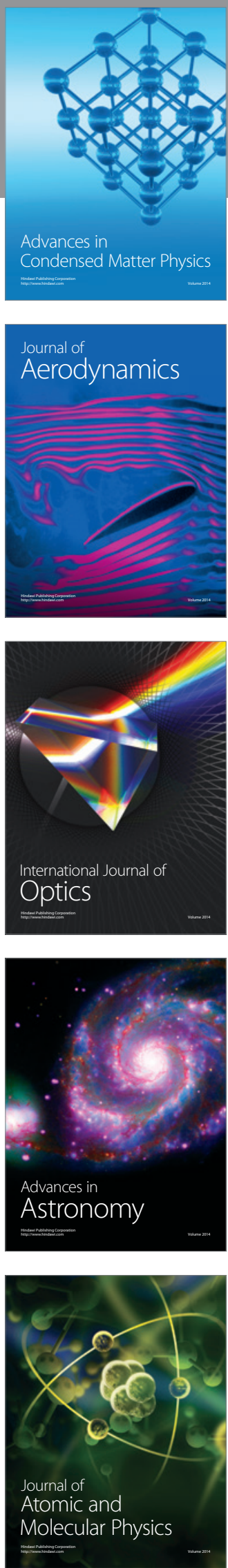